\title{
AVALIAÇÃO DA PERIODONTITE INDUZIDA EM RATOS PREVIAMENTE EXPOSTOS À CICLOSPORINA A: ANÁLISE HISTOLÓGICA E BIOQUÍMICA
}

Felipe da Silva PERALTA, Débora PALLOS, Marinella HOLZHAUSEN, Celso da Silva QUEIROZ, Lucilene Hernandes RICARDO

A imunossupressão gerada pela ciclosporina $A$ (CsA) tem sido associada à perda óssea alveolar (PO) em modelos animais com doença periodontal induzida (SPOLIDÓRIO et al., 2001, 2004). O objetivo deste estudo foi comparar através de análise histológica e bioquímica, as alterações ósseas na periodontite induzida por ligadura $(\mathrm{L})$ em ratos previamente expostos a CsA. Foram utilizados 36 animais, divididos em 4 grupos $(n=9)$ : $G C$ - controle; GCsA; GL ; GCsAL. Doses diárias de $10 \mathrm{mg} / \mathrm{kg}$ de peso dos animais foram aplicadas em CsA e GsAL por 60 dias. A ligadura foi inserida no primeiro molar inferior 30 dias após o início do experimento em GL e GCsAL. Passados 60 dias, foram coletadas amostras sangüíneas para mensuração da fosfatase alcalina (FA). Em seguida, os animais foram sacrificados e as mandíbulas processadas para análise histológica da área ocupada pelo ligamento periodontal (ALP) e células marcadas pela fosfatase ácida tartarato-resistentes (TRAP+). Os resultados não mostraram diferença estatística significativa (ANOVA, Tukey) nos valores da FA ( $p=0,1)$. Após análise de variância os resultados mostraram diferença estatística nos valores da ALP $(p=0.03994)$ e ausência de diferença estatística nos valores de células TRAP+ $(p=0.3995)$. Neste estudo, a presença da CsA não influenciou a PO causada pela periodontite induzida.

Palavras-chave: Ciclosporina A; Perda óssea alveolar; Periodontite; Imunossupressão 